\title{
Provision of Health and Social Services for Drug Addicts in the Republic of Macedonia
}

\author{
Suncica Dimitrijoska \\ sdimitrijoska@yahoo.com
}

Svetlana Trbojevik

svetlet@fzf.ukim.edu.mk

Natasha Bogoevska

natasa.bogoevska@fzf.ukim.edu.mk

Vladimir llievski

vilievski@fzf.ukim.edu.mk

University of Ss Cyril and Methodious, Faculty of Philosophy, Institute of Social Work and Social Policy

Abstract

The Republic of Macedonia experienced a rapid growth in drug addiction after its independents in 1991. The complexity of the problem represents a serious challenge for all relevant factors involved in creation of policies as well as actors in delivery of health, education and social services. Provision of necessary service required appropriate amendments of relevant laws based on the adopted international legislation. The most significant legal changes were introduction of the principles of pluralisation of social protection (Law on Social protection, 2004), that enabled emerging of new private for profit and nonprofit actors as providers of services as well as introduction of the principle of decentralization, enabling establishment of services on local level. Additionally, a number of national and local strategies and programs were developed and adopted within the system of health and social protection. These changes contributed to an increase in the number of available services offering variety of treatments responding to the individual needs of beneficiaries. Despite the increase in offered service, the state has yet to respond to the ever rising problem of addicted children. So far, little has been done for this age group of addicts that requires specialized and adjusted service provision. Provided social services are facing the problem in the sustainability of the available services provided within the nongovernmental sector that is mainly financed from foreign funds.

Keywords: system of social protection, social services, health services, drug addicts, addicted children.

\section{Introduction}

\section{Legal framework for protection of consumers of drugs, psychotropic substances and precursors}

The problem of dependence on drags is a multidimensional and complex problem that causes a series of negative consequences with economic, social, health, educational and safety character. This global problem is set high on the agenda of international organizations and agencies that sought solutions for overcoming, reducing and preventing of this phenomenon.

With the aim to introduce the phenomenon and to review the situation in the local context, we will give an overview of the main international documents without an ambition to enter in their detail elaboration. 
Universal Declaration of Human Rights guarantees the right of every person to a standard of living that will provide an adequate health and well-being for them and their family, including medical care, where mothers and children are entitled to special care and assistance.

Based on the European Charter of Patients' Rights everyone has the right to a proper service in order to prevent illnesses. Health protection amongst others should be provided through raising people's awareness, guaranteeing free of charge health procedures in regular intervals for different population groups exposed to risks, and ensuring access to all of the achievements that are a result of scientific research and technological innovations. Health care protection should be provided by creating conditions for equal access for all without any discrimination.

International Convention on Civil and Political Rights guarantees the right to life and prohibits the liberty of depriving of life, which implies health protection as well as protection from abuse of drugs and other psychotropic substances and requires countries to adopt positive measures to increase the life expectancy of people.

The International Pact on Economic, Social and Cultural Rights obliges each country to recognize the right to physical and mental health that can be achieved, and completion of this right requires the following measures to be undertaken: protection, treatment and suppression of certain diseases and creating conditions for providing medical services and assistance in all cases of disease, creation of basic conditions for good health (quality food, housing, access to quality drinking water, proper sanitation and etc.

International Convention for Abolition of all Forms of Racial Discrimination which prohibits discrimination in exercising the right to health and medical assistance. European Social Charter guarantees the right to health care, social and medical assistance and the right to social protection. It complements the European Convention on Human Rights which guarantees various rights and freedoms. The Charter has several provisions that express or imply the right to health, health and wellbeing of children and young people which are protected by Articles 7, Article 11 and Article 17. According to Article 1, health education in schools should be a priority of public health policy, incorporated in part of the curriculum, with special emphasis on: smoking, drugs, alcohol abuse, nutrition and sexual education, accessible to all children without discrimination.

The United Nations Convention against Illicit Traffic in Narcotic Drugs and Psychotropic Substances (Vienna Convention of 1988) provides improvement of cooperation between signatory countries for efficient combat against various aspects of illicit traffic in narcotic drugs or psychotropic substances as a problem that has an international dimension. It obliges countries to provide criminal and other offenses punishments depending on constitutional regulation due to possession, purchase or cultivation of narcotic drugs and psychotropic substances for personal consumption and taking appropriate measures to prevent illicit cultivation and to eradicate plants containing narcotic drugs and psychotropic substances with strict respect for the fundamental human rights.

Based on the Convention on the Rights of the Child: Countries should take appropriate legislative, administrative, social and educational measures of protecting children from illegal use of narcotic drugs and psychotropic substances as defined in relevant international treaties,aimingat prevention of use of children in illicit production and trafficking of these substances.

Domestic legislation also guarantees protection of the rights of drug users in the Constitution and other various legal acts:

Based on the Constitution (Article 39) every citizen is guaranteed the right to health care, but also notes the obligation of citizens to preserve their health and health of others. Hence, children not only have a right to health care but have the obligation to preserve their own health, which among other things implies not to the use of drugs and other psychotropic substances that endanger their health and but their responsibility to care for the health of others, more precisely not to incur other children to use drugs.

According to the Law on Child Protection (Article 9) the state and its institutions in the system should take all available measures to protect children from illegal use and other forms of abuse of children in the illicit production and trafficking of narcotic drugs, psychotropic substances and precursors.

The Health Care Law assumes provision for citizens with the right to protect their health and provides access for all citizens to general preventive measures which should ensure healthy environment, systematic health examinations and other measures and activities to prevent diseases. That assumes health care for all citizens by taking measures and activities for preservation and promotion of health, preventive, diagnostic - therapeutic and rehabilitation measures based on principles 
of: accessibility, rationality and continuity. Drug addiction as a complex social and health problem requires a long-term healing process and individual approach to persons by providing multi- professional teams for assistance.

Based on the Law on Health Insurance the insured persons are provided with basic health services that include preventive measures, more specifically health services for identification, monitoring and assessment of health condition. This is a very important Law that affects the users and drug addicts in order to implement preventive, therapeutic and rehabilitation measures, examination and assessment of health condition, treatment, rehabilitation, care, accommodation and meals in hospital setting.

Children exercise health insurance rights on the bases of their parents insurance until the age of 18 years or in case of continuing education until 26 years old. There are cases when they can exercise the rights on health insurance after reaching 26 years such as cases when due to illness they had to interrupt their schooling (Article 16). This Law and Health Care Law do not specifically regulated treatment of children addicted to drugs.

Law on Protection of Patients' Rights ensures quality and continuous health protection in line with current developments in health and medicine, in accordance to the individual needs of the patients with full respect for the dignity of their personality and in respect of their best interest and the absence of any kind of mental or physical abuse.

- $\quad$ Protection of patients' rights is based on the principles of humanity and accessibility, which is very important especially for drug addicted children, respecting privacy and human relations between the patient and health worker based on ethical principles, which is also very important for the specified group.

- $\quad$ Respecting the principle of availability, based on health services that are constantly available and accessible to all patients equally and without discrimination.

- $\quad$ Equal opportunity to protect the rights of all patients in the Republic Macedonia.

Law on Social Protection provided establishment of daycare centers for persons who use or abuse drugs and other psychotropic substances and precursors. These Centers provide the following services for addicted persons and members of their families: counseling services, information and education, employment, cultural - entertainment and leisure activities.

Law on Control of Narcotic Drugs and Psychotropic Substances prohibits dispensing medicines containing narcotic drugs, psychotropic substances or precursors to minors and persons who show signs of mental disorder. Parents, adoptive parents, guardians, teachers, health workers, social care employers and sports workers are obliged and responsible to take measures to prevent and suppress abuse of narcotic drugs and psychotropic substances among children and youth.

The Government adopted program for drug abuse, psychotropic substances and precursors in educational institutions. The Ministry of Education and Science at the beginning of each year publishes guidelines for promotion and coordination of regular educational activities related to damages caused by use of narcotic drugs and psychotropic substances on health, learning and development of children and youth. Centers for Social Work after established contact with the addicted person and their family are obliged take all necessary measures for their rehabilitation and if needed to provide referral to an appropriate health institution.

The problem of drug use and drug misdemeanor aspects are regulated in the Criminal Code which foresees sanctions for person that manufactures, sells or offers for sale or for buy to sale, hold, transfer or mediate in the sale or purchase or otherwise releases narcotic drugs, psychotropic substances and precursors as well as prescribes penalty by law for violations of public order and peace for the ones who are involved in to taking narcotics, psychotropic substances and precursors.

The Republic of Macedonia develops a strategic approach in taking measures to address this problem through adoption of a National Drug Strategy in the Republic of Macedonia (2006 -2012) and (2014-2020). The Strategy, lists separate risk groups such as addicts in prisons, victims of trafficking, Roma, athletes that use doping, young people involved in criminal groups, etc. Leading principles and objectives of the strategy are the principles for protection of human rights, guaranteed safety of all citizens in the Republic, equal opportunities for all, balanced approach, adapting to the needs of different target groups, shared responsibility and coordinated approach and the principle of availability and cost effectiveness. 


\section{HEALTH CARE FOR DRUG USERS}

Drug users are treated within the existing network of public and private health institutions. Their treatment includes: treatment in day hospitals, hospital treatment, detoxification and substances treatment. The majority of drug users are treated through day hospital treatment, where they are treated with substances, psychosocial interventions, individual or group counseling and psycho-social therapy.

Persons with problematic abuse of heron have been provided with substance methadone therapy and therapy with buprenorphine, for the sole purpose to achieve complete abstinence, to prevent development of abstinence crisis, to reduce the incidence of recidivisms, to improve their psychological and social functioning, to prevent HIV infections, to prevent contracting hepatitis $B, C$ and $D$ and to reduce involvement in criminal acts and antisocial behavior.

The largest number of person with problematic use of heroin seeks treatment with methadone. Methadone treatment program for persons who use drugs is conducted under the established protocol for performing health activities established by the Ministry of Health of the Republic of Macedonia, which refers to the use of methadone in the treatment of opiate addiction. In order to involve one person in the healing treatment, the following health tests are required: comprehensive physical and psychiatric examination, laboratory tests (general blood test, levels of fats and sugars in the bloody, test for Hepatitis $\mathrm{C}$ and HIV status).

For treatment of persons between 16 and 18 years a parent or guardian consent is required. The available treatment is not provided for persons under the age of 16 years.

The substance methadone therapy also covers beneficiaries from correctional institutions in the country.

Substance therapy with methadone is provided within the Centers for prevention and treatment of drug addiction in the following cities: Gevgelija, Bitola, Veles, Stip, Tetovo, Kavadarci, Ohrid, Strumica and Kumanovo.

In the capital city Skopje, the treatment is provided within the Center for prevention and treatment of drug abuse and other psychoactive substances-KiselaVoda, in the Department of the Clinical Center in Psychiatric Hospital „Skopje "- Skopje and in the Hospital " 8 th of September".

Treatment with buprenorphine is administrated within the University Clinic of Toxicology - Skopje. In order to begin the treatment with buprenorphine, one needs to carry out the following tests: a comprehensive physical and psychiatric examination, laboratory tests (blood test, tests on the levels of fats and sugars in bloody, tests for Hepatitis C and HIV status).

In 2014 the above mentioned health institutions have treated over 1200 patients with methadone substance therapy. Apart from the treatment in public health institutions above 150 patients have privately financed their substance therapy treatment in private health institutions. The University Clinic of Toxicology-Skopje in 2014 administered treatment with buprenorphine to 230 persons. Their treatment was covered with the public health insurance scheme by the Ministry of Health ${ }^{1}$.

Unfortunately, the number of beneficiaries that can receive methadone therapy is limited. The closed list for intake of new patients on methadone and bubrenofin therapy puts individuals in an uneven position. Patients who are not enrolled in the program and are in situation of dire need for addiction treatment and are in unfavorable position compare to other patients who receive needed health services and have uninterrupted access to service. ${ }^{2}$

In Macedonia there is a complete absence of a specially designed program for the treatment of minors for drug addiction. Drug addicted persons who are younger than 18 years instead of being included in special treatment programs, are fully marginalized and discriminated. This current problem has been more increasingly emphasized by the civil sector and indicates the violation of the rights of children and their inability to be provided with adequate health services and health care.

1Program for health condition of addicted persons in the Republic of Macedonia for 2015, Government of the Republic of Macedonia, Official Gazette no. 196/2014

2Protection on the rights of patients with the focus on persons users of drugs, Association for emancipation, solidarity, and equality of women RM-ESE. 
Civil society organizations and the Red Cross of the Republic of Macedonia are active participants in the treatment of persons who use drugs. Within the Program for reduction of drug use they provide assistance in nine different cities in the country. Their services are focused in providing: medical, social and legal assistance for persons who are receiving treatment for drug dependence, people who use drugs, and people who aspire to abstinence or are already in the phase of abstinence from drug use. The main aim of these services is to provide beneficiaries with access to health care, to advance their rights related to their health and to contribute to the process of their social integration. This program also involves families of drug users as well as professionals that work in health and social services as target groups.

The following medical services are covered under this program: basic treatment of wounds caused by prolonged or inappropriate injection of drugs, counseling and education for health protection, motivation for treatment and referral to health facilities.

\section{SOCIAL SERVICES FOR PERSONS WHO USE DRUGS}

Social protection is provided through a system of measures, activities and policies for prevention and for overcoming the basic social risks to which drug users are exposed to such as reducing poverty and social exclusion as well as strengthening of their capacities for social integration.

At the national level, the treatment for drug users is provided by public and private institutions as well as civil society organizations. Through multidisciplinary approach and continuous monitoring and technical support an appropriate response to the needs of the target groups has been established by following further decentralization and expanding of the network of services for treatment of drug users.

The principles of decentralization and pluralism can be noted in the process of social protection where provisions of services have been provided by local government, civil associations and religious organizations.

Some municipalities have adopted local strategies and action plans for reduction of drugs abuse that through certain activities aim to ensure reduction of the availability of drugs, reduction the number of persons experimenting with drug use, development of health and social services that will provide accessible and effective treatment and care for people who use drugs and harm reduction from drug use.

The rights of social protection that can be obtained by drug users are in the form of financial assistance, more precisely social financial assistance and permanent financial assistance, cash compensation for assistance for care by another person, allowance for blindness and mobility, depending on health and financial situation of the drug user.

Rights in the area of non-residential protection are: rights of social service provided for persons that cannot been obtained in other institutions.

Non-residential social protection for people who use drugs is provided in the form of daycare centers for drug users, providing services for persons who use drugs and other psychotropic substances as well as services for members of their families. The aim of these services is to provide appropriate services, information, counseling and education for work engagement and engagement in cultural, entertainment and recreational activities. The beneficiaries require immediate assistance in the process of their social reintegration after completing the program of medical treatment. The Ministry of Labour and Social Policy has established these types of day care Centers in Ohrid, Kumanovo, Strumica, Skopje and Kavadarci.

Currently the Social Work Centers offer daycare centers for persons who use or abuse drugs and other psychotropic substances. There is one faith based center in Strumica and daycare center in Ohrid. The daycare center in Strumica is a part of the multisectoral cooperation between the Ministry of Labor and Social Policy, Ministry of Health, Municipality of Strumica, Nongovernmental organization and the Orthodox Church.

The services of providing information, advice on treatment of addiction and referral to a competent institution that should be provided to children who use drugs are very limited. This category of children mainly receive assistance in kind such as food, clothing and hygienic supplies which indicates to the poor financial situation of these drug users. Part of the juvenile drug users received counseling and were referred to use services for homeless in the Shelter for homeless people in Skopje. 
The reports of Centers for Social Work has limited data on the services provided to drug using persons. Professional, advisory and counseling assistance has been offered insufficiently. Based on the available statistics for 2012 all of the Centers for Social Work (30) recorded 396 drug addicts of whom 366 were male and 30 were females. Regarding their age most of them were in the age group from 26 to 45 years 325 males and 23 females. However, based on the available data for 2013, there were 47 new registered beneficiaries. This indicates on the small number of people who sought assistance from the Social Work Centers in accomplishing some rights provided by the Law on Social Protection. There are cases where drug users were registered in the Social Work Centers not as drug users but as socially excluded persons.

A daycare centre for administration of methadone therapy has been established within the largest prison in the country since 2006. The medical facility has 120 providing treatment to drug dependent persons as well as to other patients. The assistance administered to these beneficiaries includes counseling for overcome the problems that drug addicted prisoners face. Inmates from other prisons in Skopje, Bitola and Ohrid also receive methadone substance therapy. This assistance is offered in conjunction with local treatment centers and the University Clinic of Toxicology (for buprenorphine). Apart from medicament therapy they are offered counseling for overcoming the existing risks they face with.

\section{Presentation of social services for drug users provided by NGO "HOPS" and NGO "Doverba"}

NGO "HOPS" established their first needle exchange program in the year of 1997. This program enabled them to identify other drug abuse related problems. Namely, besides the problem of sharing injecting equipment, their clients manifested needs such as attainment of health care and social care rights as well as the lack of respect for their human rights. This lead to the need to introduce additional services in the program such as medical, social, and legal services as well as counseling service, testing for HIV and offering of various educative services for drug users.

NGO "HOPS" expands its activities with the opening of two drop-in centers in Skopje in 2005 and 2006. In addition to this they develop outreach work at multiple locations, encompassing the suburbs of Skopje.

The service of providing information on identity documents refers to the provision of information on required documents for obtaining personal documents, and in the case of minors, provision of information for obtaining a birth certificates, for obtaining certificates for citizenship and alike. In this regard they have contacted 10 children, and 6 of them were referred to the competent institution for acquisition of personal documents. These persons were mainly referred to the Regional registry services and to the Regional offices of the Ministry of Justice and Ministry of Interior.

All programs of the NGO "HOPS" are harm reduction programs, except for the program in Gevgelija. The services provided in Gevgelija are administrated by a social worker, and include: help and assistance in obtaining documents, assistance for obtaining social and health rights, counseling, education, motivation for treatment and referrals to appropriate social and health institutions. In the period from 2012 to 2014 HOPS have administered a total of 27.297 social services.

The data of NGO "HOPS" on work with children who use drugs shows that during 2015, they have provided assistance in information to 11 children about the necessary documentation for obtaining health insurance. They have assisted 8 children and their parents to connect with the Health Insurance Fund as a responsible institution where they can obtain their right to health care. Also, they have offered individual counseling assistance to a number of children.

NGO "Doverba" primarily offers social and counseling services. By provision of adequate financial and logistical assistance to drug users who are not in position to initiate the process of obtaining documents on the health care and social care.

The fieldwork in association "Doverba" started functioning in 2002 and provides the following three types of field work: outreach in frequent places where drug users meet; fieldwork in the homes of drug users conducted mainly on the initiative of user's parents especially in case when they are unable to motivate their children to sought help in the counseling centre; and field social work interventions that include offering mediation and technical assistance in obtaining documents needed for health insurance, social protection or any other kind of mediation and assistance in contacts with public institutions.

The process of social services begins with establishing contact with drug user, conducting personal needs assessment, planning services to mitigate the risks in his/her surrounding. Planning the support that will enable connection with the primary social network of beneficiary, planning development of the client in areas that will contribute to improvement of participative interaction in the surrounding. Social services may be administered as day care services in a community, advisory-therapeutic and social educative services as well as services for independent living. Offered services are 
complimentary and related to other offered services. The services include a plan for continues monitoring and evaluation of planned and achieved goals and revision of the planned activities depending on the changes occurring at particular drug user and their environment.

An indirect treatment causes changes in the users surrounding that affects the unproductive interaction of drug user. Mainly referring to material and economic aspects of environment, socio psychological aspect is a result of these two aspects of the environment related to other social factors such as social compensation of the environment.

The direct treatment is applied when the problems of the user are of psychological and somatic nature as well as when problems are overcomed. The social worker is in a role of therapist working on the personality issues, attitudes, value system, emotions and behavior as well as on stimulation, activation and development of current potentials of the person with the aim of improvement and social integration in the environment. Besides counseling that is used in the direct treatment they are implementing psychotherapeutic method, group therapy, psychodrama, reality therapy, cognitive therapy, and other methods and techniques.

In practice, they usually combine indirect and direct treatment which basically represents the complex treatment that is needed due to the complexity of the problem that drug users experience.

Fieldwork aims at establishing contacts with hard to reach population that already has risky behavior of drug abuse. Field work is only part of the social health services that are applied for addicts and is accomplished through education and distribution of educative and preventive materials as well as referral to institutions that offer services for drug users. Fieldwork is highly flexible and adapted to the needs of drug users and is accomplished through three approaches: outreach in public, outreach to the institution and outreach in homes, in cases where drugs are used in homes/apartments of addicts.

\section{FINDINGS AND ACTIVITIES OF THE OMBUDSMAN FOR CHILDREN USERS OF DRUGS}

The Ombudsman has investigated the problem of drug use through in a longer period of time through visits to institutions responsible for the healing and treatment of drug users and acting upon complaints or institutionally initiate inquiries. According to the findings of the Ombudsman, the number of children users and addicts to drugs and other psychotropic substances is constantly growing whereas the starting age among children is decreasing (first experiences are noted at the age between 7 and 8 year old children). Predominantly, these are children without parents or parental care and are from the Roma community.

The Ombudsman has identified:

- $\quad$ Lack of appropriate facilities and human resources in the network of health care facilities as well as lack of adopted treatment protocols, treatment and rehabilitation of children who use drugs,

- $\quad$ Lack of strategy and special measures for separate treatment of children that differs from treatment of adults.

- $\quad$ Lack of opportunities for placing children in special institutions for healing and treatment.

- Insufficiency of space and appropriate conditions for therapeutic treatment and accommodation for addicts, lack of separate unit for drug addicts in the Psychiatric Hospital "Skopje", and space for protection and inclusion of all interested addicts to participate in the treatment of addiction.

- Insufficient number of centers for addiction and clubs in Skopje and other municipalities where there is an emerging need to treat addicted persons.

The Ombudsman has repeatedly addressed the authorities with a request to seriously consider this problem and proposed to undertake all possible measures (legislative, administrative, social and educational) for preventing children who use drugs and become addicted, especially to establish health care institutions for appropriate treatment, support and care of children users drugs. Considering the raising trend in the number of addicts and having in mind the age group of affected children, the Ombudsman recommends introduction of educational programs in schools to prevent and reduce drug addiction and other psychoactive substances so children from the earliest age will be informed about the damage and the consequences from addiction.

Additionally, the Ombudsman recommended continuous education of the general population as well as of health workers about modern trends in medicine in the field of addiction prevention and engaging society in more frequent and timely medical checkups in order to provide early detection of addictions. 
Because children are more frequent in becoming users of drugs and other psychotropic substances, the Ombudsman considers as necessary the following:

- $\quad$ The state should adopt specific strategy;

- Special measures should be undertaken for the proper treatment of children different from the treatment of adults;

- The need to create opportunities for placing children in separate institutions for healing and treatment;

- $\quad$ Active involvement of all institutions and institutional bodies which are authorized and obligated to take care about the rights of child: health, social, educational and other aspects.

- $\quad$ Provision of appropriate protection and health care for children.

- Children should be provided with protection and care necessary for their well-being and the institutions, services and facilities responsible for the care or protection of children shall be in accordance with the standards established by competent authorities, particularly in the area of safety and health, the number and suitability of staff in the institutions as well as professional supervision.

- $\quad$ Establishing a day care center for children who abuse drugs through inter-sector cooperation of the Ministry of Health and Ministry of Labor and Social Policy.

\section{CONCLUSION}

Treatment of drug users in the Republic of Macedonia dates from the late 1970s and early 1980s, with the introduction of substitute methadone therapy. Until the adoption of the first National Strategy on Drugs in 2006 this type of treatment was centralized. In 2006, the Ministry of Health opened 10 new offices for treatment and harm reduction of drug use, including methadone maintenance treatment in the cities of Strumica, Kumanovo, Stip, Ohrid, Gevgelija, Bitola, Veles, Tetovo and Kavadarci and one in the main prison in Skopje. These services work with the support of the Ministry of Health, Ministry of Labor and Social Policy, Social Work Centers, the local community and NGOs and their work was initiated within the program for building coordinative response to HIVIAIDS in the country (supported by the Global Fund). This development has increased the coverage on the territory of the Republic of Macedonia with substance methadone treatment, the availability of therapeutic services and strengthening institutional capacities. In addition, a growing number of health professionals operate effectively at the local level through a multidisciplinary approach and by introducing a new model for continuous monitoring and technical support in order to have an adequate response to the needs of the target groups.

The implementation of the Macedonian National Drugs Strategy (2006-2012), was followed by further decentralization and expansion of the network for treatment services and harm reduction of drug use, including methadone maintenance treatment, with the opening of two additional centers in Skopje as well as two additional centers in prison facilities, one in the city of Bitola, and one in the investigation prison "Skopje", in Skopje.

The introduction of new models for treatment of dependent drug users was accomplished with the introduction of buprenorphine in 2009, within the highest levels of health care, tertiary health care, at the University Clinic of Toxicology, Clinical Centre Mother Teresa in Skopje. Buprenorphine is used for detoxification and substitution therapy.

At national level, drug treatment is provided in different health, social and civil organizations. Predominantly, drug treatment is available in the framework of public health services, making the public sector leading actor in treating drug addiction with medicaments. Also, four private psychiatric services offer treatment of drug addiction. National system for treatment covers outpatient and hospital treatment, detoxification and substitutive therapy. Most treated drug users receive outpatient treatment which offered opioid substitution therapy, psychiatric interventions, individual or group counseling and social and psychological therapy. Inpatient drug treatment consists of psychosocial interventions with pharmacological assistance in terms of treatment for addiction withdrawal. Detoxification can take place in an outpatient or in hospital settings.

The Association of Social Workers of the City of Skopje in 2003 actively operates the SOS line for assistance of drugs as a permanent service to all citizens in the Republic of Macedonia. Through a toll-free number citizens can get information on the types of drugs, their effects, harmful consequences of their use for the treatment in domestic and foreign institutions, as well as information on HIV / AIDS, sexually transmitted infections, and assistance in scheduling a free counseling provided by expert. 
So far, there were three day care centers opened for people who use or abuse drugs and psychotropic substances. Programs for harm reduction from drugs are established in 13 cities in the country.

Despite the actions taken, the problem of drug abuse in the country is rapidly growing. It is estimated that in the Republic of Macedonia $6000-8000$ persons can be considered as addicts on heroin and may face serious health and social consequences.

National Drugs Strategy of the Republic of Macedonia (2014-2020) and the Action Plans and activities that address new challenges identified in recent period, include:

- The need to improve the quality, diversification (in terms of sensitivity to cultural differences, gender, age, ethnicity) and the availability of centers for substance therapy with methadone,

- The need for reorganization, decentralization and increasing the availability of tertiary primary to primary level, treatment of drug addiction with psychotropic substances -Buprenorfine.

- $\quad$ The mandatory need for administration of psychiatric services in drug addiction treatment in specialized clinics.

- $\quad$ The need for conducting research and analysis on the reasons for the increasing number of deaths as a result of methadone overdose.

- $\quad$ Continuous high prevalence of mortality associated with drug abuse.

- The need for conducting analysis for the high incidence of road accidents deaths related to possible use of psychoactive agents as a risk factor.

- Growing trend to use of more psychoactive substances at the same time, including drugs containing psychotropic substances.

- Challenge and the dynamics of illegal drug markets, including changing of routes for transporting drugs across the borders drug trafficking, the use of new communication technologies.

- $\quad$ Preventing the diversion of chemicals that can be misused as precursors for illicit manufacturing of drugs.

- Emerging trend in the EU countries that is present in the country with appearance of new psychoactive substances.

- Development of social services for drug users at local level.

- Designing social protection programs specifically focused on assistance and support for children who abuse drugs.

\section{References:}

Association HOPS, 2015. Drugs- politics and practices, Association, Options for healthy life- HOPS, no 1., October 2013, Skopje

Budzhakoski S. (2002) Prevention of Drug Abuse, Ohrid

Dekov V., 2015. Future of the programs for harm reduction from drug abuse in the Republic of Macedonia, Skopje, Association for Options for Healthy Fife "HOPS"

Dekov V. Ignjatova L., H. Jankulovski, Kostovski D., M. Toseva (2006) Harm reduction and HIV-HOPS Healthy Options Project Skopje

Dimitrievski C. (2011) Improvement of the right of access to social and health services for Roma who use drugs, HOPSHealthy Options Skopje

Government of the Republic of Macedonia, 2013, National Drugs Strategy of the Republic of Macedonia (2014-2020), Skopje: Government of the Republic of Macedonia

Krusharovska, N., 2012.Whether and how children are protected from abuse of drugs and other psychotropic substances? Round table on "Protecting children from abuse of drugs and other psychotropic substances" Skopje

Law on Social Protec[on -o[cial consolidated text (O־cialGazele of the Republic of Macedonia no

148/13, 164/13, 38/14, 44/14, 116/14, 180/14, 150/15, 192/15)

Law on Child protec[on (O־cialGaze匹eof the Republic of Macedonia no 23/13, 12/14, 44/14, 
144/14, 10/15, 25/15, 150/15, 192/15)

Law oh Health Protec[on (O־cialGaze[e of the Republic of Macedonia no 43/12, 145/12, 87/13, 164/13, 39/14, 43/14, 132/14, 188/14, 10/15, 61/15, 154/15, 192/15)

Law for Health Insurance (O־cialGazere of the Republic of Macedonia no 25/2000, 96/2000, 84/2005, 6/2009, 113/2014, 129/2015)

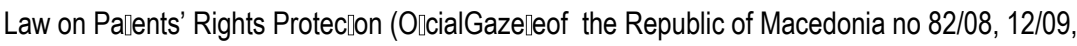
$53 / 14,150 / 15$

Law on Social Protec[on -o[cial consolidated text (O־cialGaze[e of the Republic of Macedonia no $148 / 13,164 / 13,38 / 14,44 / 14,116 / 14,180 / 14,150 / 15,192 / 15)$

Law on Child protec[on (O「cialGaze-eof the Republic of Macedonia no 23/13, 12/14, 44/14, 144/14, 10/15, 25/15, 150/15, 192/15)

Law oh Health Protec[on (O־cialGazeГe of the Republic of Macedonia no 43/12, 145/12, 87/13, 164/13, 39/14, 43/14, 132/14, 188/14, 10/15, 61/15, 154/15, 192/15)

Law for Health Insurance (O[cialGaze[e of the Republic of Macedonia no 25/2000, 96/2000, 84/2005, 6/2009, 113/2014, 129/2015)

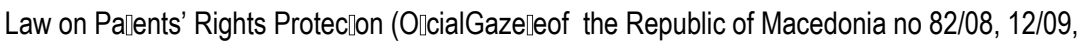
$53 / 14,150 / 15$

Law on Social Protection -official consolidated text (Official Gazette of the Republic of Macedonia no 148/13, 164/13, 38/14, 44/14, 116/14, 180/14, 150/15, 192/15)

Law on Child protection (Official Gazette of the Republic of Macedonia no 23/13, 12/14, 44/14, 144/14, 10/15, 25/15, 150/15, 192/15)

Law oh Health Protection (Official Gazette of the Republic of Macedonia no 3/12, 145/12, 87/13, 164/13, 39/14, 43/14, $132 / 14,188 / 14,10 / 15,61 / 15,154 / 15,192 / 15)$

Law for Health Insurance (Official Gazette ofthe Republic of Macedonia no 25/2000, 96/2000, 84/2005, 6/2009, 113/2014, 129/2015)

Law on Patients' Rights Protection (Official Gazette of the Republic of Macedonia no 82/08, 12/09, 53/14, 150/15)

http://ombudsman.mk/upload/documents/2012/TM-Zavisnici\%20od\%20droga.pdf 